\title{
Do Aid Donors Plant the Grassroots? Evidence from a Randomized Field Experiment in the US and Uganda
}

\author{
Danny Walker \\ George Washington University, Washington, USA
}

\begin{abstract}
Recent literature dealing with nongovernmental organizations (NGOs) claims that NGOs have little incentive to base their decisions and strategies on local needs and instead are governed largely by their current and prospective donors (McGann \& Johnstone, 2006; Prakash \& Gugerty, 2010; Bollen et al., 2005). To test this claim, I have created a quantitative experiment in the US and Uganda in which organizations were randomly assigned to a control group or one of four treatment groups based on the main stakeholders of the NGO market—donors, local government officials, project beneficiaries, and NGO peers. In each group, organizations were invited to take a survey and were told that the results of their survey would be published to one of these four stakeholder groups. Thus, differences in response rates between groups are attributed to differences in the degree of concern that NGOs felt about the opinions of a given stakeholder. I hypothesized that NGOs care more about the opinions of their donors than other stakeholder groups and found support for this hypothesis among NGOs in the
\end{abstract} US.

Keywords: Nongovernmental organizations, field experiments, aid accountability, Uganda

\section{Introduction}

[The] main reason for an NGO to be accountable is that they can continue to get money and continue to do their actions in the future. I think that accountability is a very private relationship between the donor and the NGO and I don't see that public vetting would pressure an NGO to produce better results or to do a better job at implementing their activities (Anonymous NGO Country Director, Kampala, Uganda).

Do NGOs care about the opinions of their donors more than other stakeholders such as their beneficiaries, local government officials, and/ or NGO peers? McGann and Johnstone (2006) argued that, "The current body of literature... has not examined the problems created by what can be called a crisis of transparency and accountability, an issue that looms on the horizon for the entire NGO sector" (p. 66). Such a crisis leads to the possibility that NGOs value the opinions of their donors more than the opinions of other stakeholder groups, even their own beneficiaries.

Current literature supports this possibility: Prakash and Gugerty (2010) noted that,

Arguably, nonprofits should [be] evaluated in terms of their success in achieving their mission of serving beneficiaries. [However], the reality of resource dependence suggests that donors' preferences often take precedence. [Excessive] concerns regarding accountability to donors might lead some nonprofits to neglect their responsibility towards beneficiaries. (p. 4)

Danny Walker, MPP, Trachtenberg School of Public Policy \& Public Administration, George Washington University. 
If such accountability structures exist, they could definitely distract NGOs from assessing and achieving local goals. However, the literature has only addressed these issues in theory and limited qualitative analysis. In this study, I seek to empirically test whether NGOs prioritize donors over beneficiaries.

I performed a randomized field experiment by gathering contact information from organizations in both the US and Uganda and randomly assigned them into control and treatment conditions. In each group, NGOs were invited to take a short survey and told that the results of this survey would be published to a certain stakeholder-donors, government officials, beneficiaries, or NGO peers - by way of an online database. Response rates within each randomized stakeholder group were then compared to each other to learn to which stakeholder NGOs were most interested in reaching with the information. Response rates were lower than hoped within each sample; however, there are some tentative outcomes of interest and some unexpected findings that have potentially fascinating implications for follow-up research.

Accountability prioritizing is expected due to information asymmetries in the market. On the stakeholder side, a lack of coordination among NGOs to standardize accountability mechanisms yields only contextual knowledge about NGO activities. Thus, stakeholders are forced to base funding decisions on incomparable criteria. On the NGO side, a lack of coordination among stakeholders to standardize selection techniques leads to a broad spectrum of stakeholder goals and expectations. Thus, NGOs are forced to prioritize their accountability practices as they seek to appease multiple stakeholder groups simultaneously. Both of these market attributes - fluctuant funding decisions and multiple accountability structures-give NGOs strong incentives to focus resources on the most cost-effective option among stakeholder groups which, in this case, is the donor group.

Due to this theoretical framework, the singular hypothesis of this study is that NGOs would respond most if they thought their surveys were being published to donors in comparison to the other stakeholder groups. However, I was surprised to find that while this hypothesis found support in the US sample, it did not in the Ugandan sample. This implies potentially interesting differences between the two NGO markets, which I explore in Section 5 (Results and Discussion).

I proceed in five sections. First, I review the context of NGO literature and discuss its most current developments. Second, I will explain information asymmetries as the theoretical framework in which my study operates. Third, I will overview my research design and methods, and fourth, I will discuss my results and their substantive implications. I then conclude with suggestions for future research in this area.

\section{Relevant Literature}

During the past sixty years, there has been a literal deluge of the nongovernmental organizations (NGOs) internationally. However, large and small stakeholders of the NGO market have had little information on which to base policy and funding decisions and so aid allocation and support have been scattered almost to the point of being random. Because of this, detrimental information asymmetries have arisen and been perpetuated in NGO markets - there is little consistency as to how NGOs signal their credibility to potential stakeholders and there is little agreement among stakeholders as to how to choose which new organizations to support.

In an attempt to mitigate this confusion, literature has shown that stakeholders have begun to require that evaluations be performed by their contracted NGOs (Thomas, 2010). However, although evaluations are now relatively frequent, NGOs are rarely provided with any stakeholder expectations as to what should be evaluated and as to how policies or practices should be improved (Bourguignon \& Sundberg, 2007). Also, evaluations are 
rarely shared with anyone except those requiring them and are rarely used to help make future partnership decisions. This has been shown in current literature to only exacerbate information asymmetries-NGOs produce evaluations, which are strictly contextual (Bollen et al., 2005; Hansmann, 1987) and stakeholders require little comparable information as to the quality of a given organization (Desai \& Yetman, 2005). This has led to a broad spectrum of evaluation techniques on the NGO side of the market and countless selection methods on the stakeholder side, an environment that has proven unfavorable to NGO improvement (Edwards \& Hulme, 1998).

What is more, NGOs are often expected to account to several different stakeholder groups simultaneously (Johnson \& Prakash, 2006). As noted by Edwards and Hulme (1998),

Multiple accountability presents any organization with problems, particularly the possibilities of having to "over-account" (because of multiple demands), or being able to "under-account", as each overseeing authority assumes that another authority is taking a close look at actions and results (p. 16)

In such an environment, there can be large costs to NGOs in time and resources as they seek to appease variant expectations both current and potential.

As a characteristic of this setting, literature has suggested that donors occupy the central role in influencing NGO behavior as compared to the other stakeholder groups (Barr et al, 2005). In an NGO market where the costs of bridging information gaps are high, NGOs will gravitate toward their donors or potential donors, often at the expense of other groups (Flack \& Ryan, 2005; Prakash \& Gugerty, 2010). However, although this argument is logically sound, it is an empirically unsupported claim that my experiment seeks to test.

Recent authors are coming closer, but most focus their studies exclusively on donor-side variables of the market (Deaton, 2010). What is more, these studies mostly focus on large aid institutions such as USAID in order to analyze macro variables such as democracy promotion (Knack, 2004; McMahon, 2001), levels of aid autonomy from national governments (Milner, 2004), foreign policy and diplomatic advantages (Atwood et al, 2008), investment risks due to state fragility (Baranyi \& Kristiana, 2005), and policy-aid feedback channels (Bourguignon \& Sundberg, 2007). Thus, the attributes of donor-NGO interactions themselves are largely ignored.

Studies that have looked from the NGO side also tend to emphasize output variables such as increases to local education or income (Miguel \& Kremer, 2004; Duflo, 2004; Banerjee, 2007). The few articles that have observed NGO structure and market characteristics look mostly at bias and even dishonesty in reporting as a symptom of local market inefficiencies or as caused by defects in human and/ or social capital (Center for Global Development, 2006; Chapman \& Quijada, 2009). However, authors are recognizing more the need for studies that observe NGO-stakeholder interactions. For example, Burger and Owen (2008) produced a study in which they compared NGO reports of activities to beneficiary reviews of the same activities of over 300 organizations in Uganda. This was meant to uncover aggregate discrepancies between the two reporting types and the authors do provide empirical support that such discrepancies exist (2008). However, although this study and others seek to explain important aspects of NGO behavior, they ignore a comprehensive theory of NGO-stakeholder interaction and any quantitative exploration of accountability trends within such a theoretical structure. In my current study, I seek to reconcile current literature by outlining such a theory and showing NGO trends (and possible biases) of accountability within that theory. 


\section{Theory and Hypothesis}

Accountability biases in the NGO market begin with the risks caused by information asymmetries. In today's NGO world, information asymmetries on both sides of the market can prevent NGOs from getting meaningful attention and stakeholders from being provided with appropriate information.

On the one side, stakeholders are taking huge risks in trusting NGOs with funds and support when they have little comparable information as to the credibility of such organizations. And on the other side NGOs are taking their own risks in employing evaluation strategies that may not be consistent with stakeholder expectations or goals. These risks lead to incentive structures that are impossible to overcome without widespread coordination - it would be futile in this environment for any individual NGO to try to bridge such information gaps. Thus, NGOs have strong incentives to gravitate toward their most cost-effective option and choose to be accountable to their donors more than to their other stakeholders, including even their own beneficiaries (Kilby, 2004; Barr et al., 2005; Ben-Ner, 1994).

\section{The Stakeholder Side: Comparability Gaps}

At the NGO end of the market, I have shown the development of accountability practices such that evaluations are now frequently required. However, due to the large spread of NGO structures and activities, individual NGOs have little ability to see cross-organizational comparisons on which to base evaluations. Thus, there is little (if any) coordination among NGOs to form standardized principles of evaluation. And what is more, any coordination among NGOs in terms of evaluation standards could lead to more direct competition for funding and so NGOs have little incentive to structure their evaluations such that they can be immediately compared to their NGO peers.

The fear of competition and the lack of coordination cause NGOs to produce strictly contextual evaluations - most are based on small baseline studies that NGOs perform at the beginning of a given project initiative (USAID, 2011). Such contextual evaluations are attractive to stakeholders, but are simultaneously useless in promoting informed decision making as to funding and support. The evaluations are attractive because they give the perception of meaningful achievement. Stakeholders can easily see improvements due to NGO activities as compared to the NGO's baseline study. Thus, results seem substantively significant, but actually give no context as to their magnitude or importance. This constitutes what I call the "comparability gap" between NGOs and stakeholders - stakeholders have no knowledge of NGO qualifications as compared to other organizations.

Due to the comparability gap, stakeholders have no meaningful information by which to lower risk in their funding decisions. Instead, stakeholders may look to more superficial characteristics such as an organization's size or grant history (Burger \& Owens, 2011). They may also try filtering strategies such as requiring massive grant applications or even stipulating fund use before applications are accepted. However, these strategies and practices do not trace to any predictable trends in decision-making or funding allocation. Thus, from an NGO perceptive, grant distribution may seem almost random.

If NGOs perceive stakeholder funding decisions to be random, the most rational strategy would be to gravitate toward the stakeholder group that issues the highest payoff. Thus, this supports the theory that NGOs would be expected to assign most of their accountability and evaluation resources toward donors, even at the expense of other stakeholder groups. This occurrence demonstrates the hypothesis of my study:

$\mathrm{H}_{1}$ : NGOs are more willing to be accountable to donors than to other stakeholders. 
I have shown that this hypothesis is strongly supported by theories found in current literature. In my tests, I expect to find that response rates in the donor group of each sample will be statistically higher than the response rates of all other groups.

\section{The NGO Side: Expectation Gaps and Costs}

The perception of a randomized funding environment as described above implies that stakeholders have not coordinated to standardize credibility expectations. Thus, across all stakeholder groups there are large variances as to what is expected from selected or prospective partners. And what is more, since NGOs simultaneously encounter multiple stakeholder groups, it would be unhelpful for any one stakeholder to standardize its expectations. In fact, without coordination, standardization of expectations among stakeholders would be unnecessarily burdensome to NGOs who would have to concurrently try to match the differing requirements of each distinct group.

In the first diagram of Figure 1, NGOs experience several stakeholder groups which all have distinct expectations as to how the NGO should perform its work and what results should be achieved. Because of these differences, the NGO is forced to try to appease each group separately. In the second diagram, all stakeholder groups have coordinated and so have identifying a unified set of expectations. Thus, the NGO can work to achieve the expectations of all stakeholder groups without being forced to prioritize.
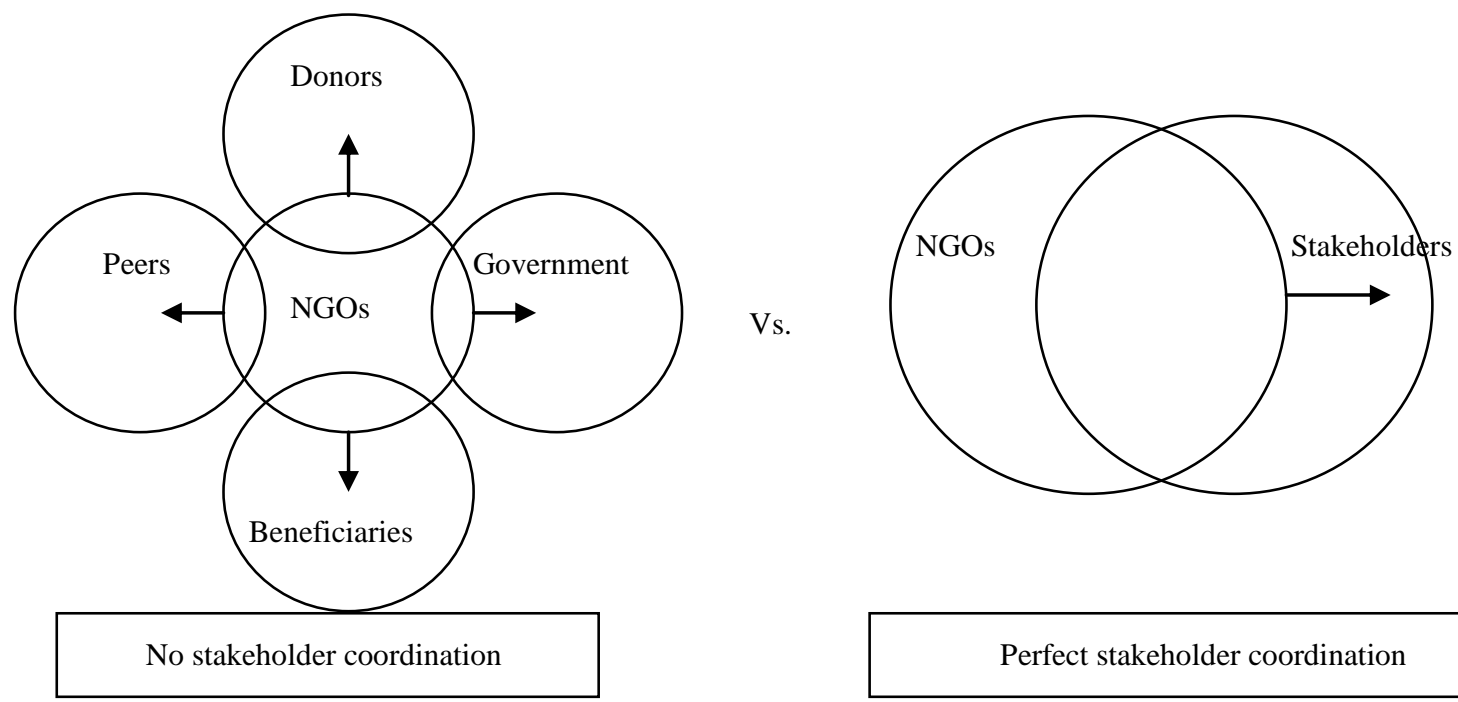

Figure 1. Coordination issues among stakeholder expectations.

The lack of coordination among stakeholders causes what I call the "expectation gap" or the lack of standardized expectations as to how NGOs should structure their work and subsequent improvements. Due to the expectation gap, I have argued that NGOs are forced to prioritize their accountability practices in order to appease stakeholders. Because of this, NGOs have strong incentives to adhere to accountability styles that cater to the desires of their most preferred stakeholder group - thus using accountability arrangements as a sort of advertising technique.

In such an environment, there is a high probability of bias reporting among NGOs (Michaelowa \& Borrmann, 2006). Also, there is the expectation that NGOs would view catered accountability to donors as the most cost-effective strategy for advertising. This would be especially true in cases where donors were located somewhere outside an NGO's immediate proximity and thus would be unable to verify biases in advertising 
and reporting mechanisms.

\section{Theoretical Summary}

Due to incentives caused by both sides of the market, I have argued that NGOs have clear motivations for focusing their accountability efforts on current and potential donors. This is based on the argument that NGOs have strong incentives to be interested in the expectations of stakeholder groups insofar as these expectations imply future funding and/or support.

Credibility and expectation gaps lead to a cycle that perpetuates asymmetries and detrimental market characteristics. These mechanisms are summarized by bringing together both the credibility and expectation gaps as illustrated in Figure 2.

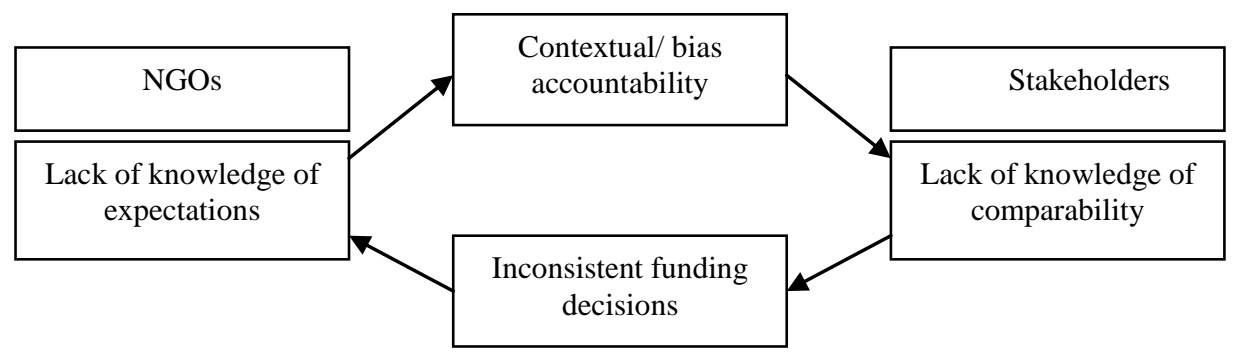

Figure 2. Information asymmetries in the NGO market.

This shows that stakeholders and NGOs experience information gaps which have adverse effects on both sides of the market. NGOs lack knowledge of stakeholder expectations causing contextual and even bias accountability practices. Stakeholders lack knowledge of NGO credibility causing variance in funding and support decisions. Because these market characteristics are self-perpetuating, I have shown that attempts by individual organizations to overcome them on either side would be ineffective. Thus, in the absence of large-scale coordination, NGOs have incentives to favor donors over other stakeholder groups.

Table 1

Representation of Control and Treatment Groups

\begin{tabular}{ll}
\hline Group & The results of this survey will be published... \\
\hline Control & ...to an online database; you will remain anonymous \\
Treatment 1 & ...to your project beneficiaries \\
Treatment 2 & ...to the donors of your organization \\
Treatment 3 & ...to local government officials in your area \\
Treatment 4 & ...to other NGOs working on similar development projects \\
\hline
\end{tabular}

Notes. Copies of the original emails are found in Figures A1-A5 of the Appendix.

\section{Research Design}

For my tests, I use an original database of NGOs from both the US $(n=874)$ and Uganda $(n=835)$. These data were compiled with permission from local contacts and public databases. In each sample, I randomly assigned organizations to a control group or one of four treatment groups constituting NGO stakeholders: donors, beneficiaries, local government officials, or peer NGOs. I then sent emails to the organizations in each group inviting them to take a short survey. I stated that the information from each survey would be published to an online database and that the stakeholder in whose group they were assigned would have access to said 
database (see Table 1).

By comparing the response rates of each of these groups, I was able to observe statistical differences in NGO willingness to account within each group, thus exposing to whom NGOs felt most accountable. On the survey, I asked NGOs to report a variety of characteristics (see Table 2).

Table 2

Description of Variables

\begin{tabular}{|l|l|l|}
\hline Variable & Coding & Description \\
\hline Years in operation & \# of years & The number of years an organization has been operative. \\
\hline Staff & \# of employees & The organization's current number of full-time staff \\
\hline Staff (t-1) & \# of employees & Number of staff one year ago \\
\hline Governing Board & $\begin{array}{l}1=\text { have a governing board, } \\
0=\text { otherwise }\end{array}$ & Binary: Whether or not the organization has a functioning governing board \\
\hline Term limit & \# of years & $\begin{array}{l}\text { The number of years the executive authority (or authorities) of the organization } \\
\text { is allowed to stay in that position within reelection or reappointment }\end{array}$ \\
\hline Proposals & \# of proposals submitted & $\begin{array}{l}\text { The total number of grant funding proposals submitted by the organization in } \\
\text { the past year }\end{array}$ \\
\hline Approvals & \# number of grants received & The total number of grant proposals approved for funding \\
\hline Approval ratio & total grants/ total approvals & The ratio of proposals to approvals \\
\hline Collaboration & frequency scale: $(1-6)$ & $\begin{array}{l}\text { The number of times an organization collaborated with another NGO in the last } \\
\text { year; ranges from 1, "Less than once" to 6, "More than six times" }\end{array}$ \\
\hline
\end{tabular}

These variables provided useful information about each organization and allowed me to run randomization checks on both samples. Through these checks, I found that NGO characteristics were distributed equally within all treatment groups. The results of these tests can be reviewed in Tables A4 and A5 in the Appendix. I also run tests to assess any statistical differences between US and Ugandan NGOs based on these variables. I found that the samples were not statistically different except in Years of operation in which US NGOs were, on average, about seven years older than Ugandan NGOs with an expected range (at the 95\% level) of about twelve to two years. These results can be viewed in Table A6 in the Appendix.

\section{Results and Discussion}

The results of my study were varied. In the US sample, organizations were consistent with my hypothesis and responded more to donors when compared to other stakeholder groups. However, the donor group was the only stakeholder group that was statistically above the control group. In the Ugandan sample, the results were a bit different - NGOs responded to all stakeholder groups more than the control, but no single stakeholder group outpaced the others.

\section{US Sample}

Among US NGOs, the donor group far outpaced all other stakeholder groups. Statistically, accountability to donors was significantly higher at least at the 0.05 level in every case, its most significant difference being above peer NGOs (probability that donor group was equal to the NGO peer group $(p=0.0009)$ and its least significant effect found above the government and control groups $(\mathrm{p}=0.0287)$ (see Figure 3$)$.

Notice that the donor group saw significantly more responses than any of the other groups. In fact, donors constituted about $36 \%$ of all respondents in the US survey. Thus, an average organization would be about $16 \%$ more likely to respond to the survey if told that its results were being published to donors (as compared to the control group). The effect is even stronger between organizations asked to account to donors and those asked to 
account to NGO peers: an average organization would be about $25 \%$ more likely to respond to donors in this case. Table 3 summarizes differences in means between all treatment groups and the control.

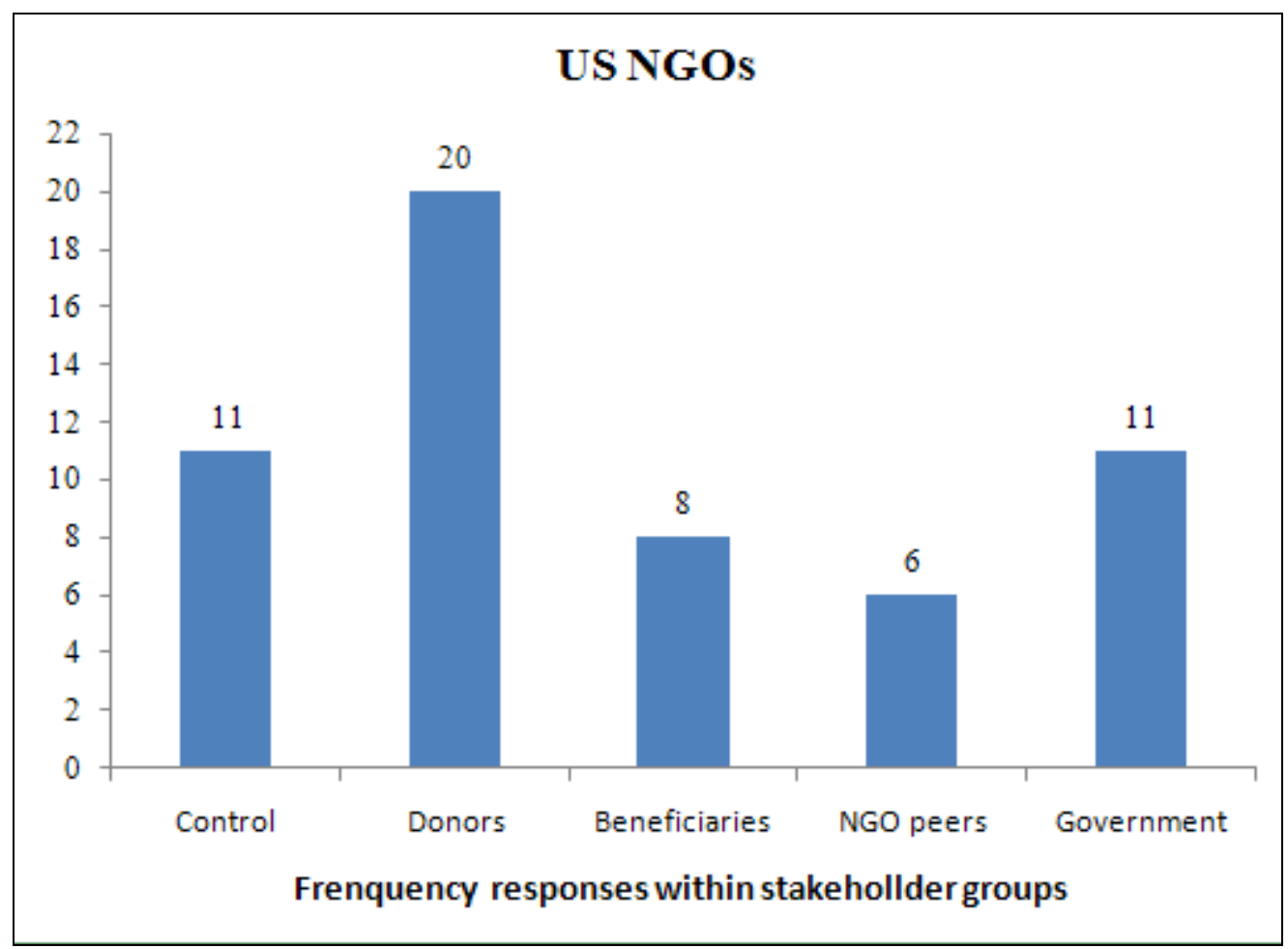

Figure 3. Response rates among US NGOs.

Table 3

Differences in proportions among US NGOS

\begin{tabular}{llllll}
\hline Stakeholder group & $\mathrm{p}<$ Control & $\mathrm{p}<$ Donors & $\mathrm{p}<$ Beneficiaries & $\mathrm{p}<$ Peers & $\mathrm{p}<$ Government \\
\hline Control & - & 0.9713 & 0.225 & $0.094^{*}$ & 0.5 \\
Donors & $0.0287^{* *}$ & - & $0.0044^{* * *}$ & $0.0009 * * *$ & $0.0287 * *$ \\
Beneficiaries & 0.775 & 0.9956 & - & 0.2839 & 0.775 \\
Peer NGOs & 0.906 & 0.9991 & 0.7161 & - & 0.906 \\
Government & 0.5 & 0.9713 & 0.225 & $0.094 *$ & - \\
$n=$ & 11 & 20 & 8 & 0.1071 & 0.1964 \\
mean $=$ & 0.1964 & 0.3571 & 0.1429 & 0.3121 & 0.4009 \\
std. dev. & 0.4009 & 0.4835 & 0.3531 & .
\end{tabular}

Notes. One-sided difference in proportions tests. Each cell features the probability that the mean proportion of the row group is lower than the mean proportion of the column group. Summary statistics are also reported for the column group in the last three rows. Statistical significance is reported at the $0.01(* *), 0.05(* *)$, and $0.1(*)$ levels.

The significance of responses in the donor group denotes a strong tendency among NGOs to be accountable to their donors over any of the other groups. Especially pertinent are the results between donors and beneficiaries which imply that NGOs are more likely to be accountable to those financially supporting them than to the people they propose to aid. Thus, although organizations may advertise "grassroots" development or development aid determined by local needs, these results show that NGOs may only be accountable to beneficiaries when it is made convenient by their funding environment. 


\section{Uganda Sample}

Ugandan NGOs did not see significant effects between treatment groups, but all stakeholder groups saw more responses than the control group (see Figure 4).

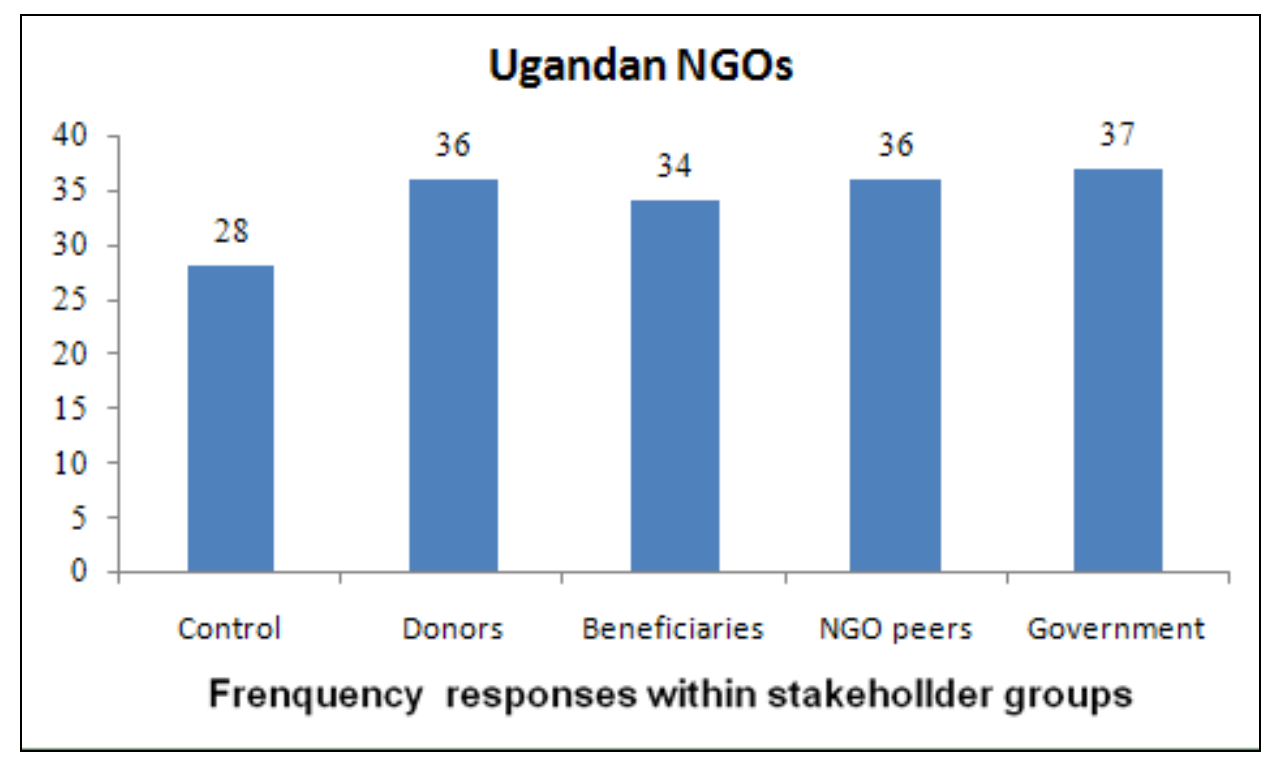

Figure 4. Response rates among Ugandan NGOs.

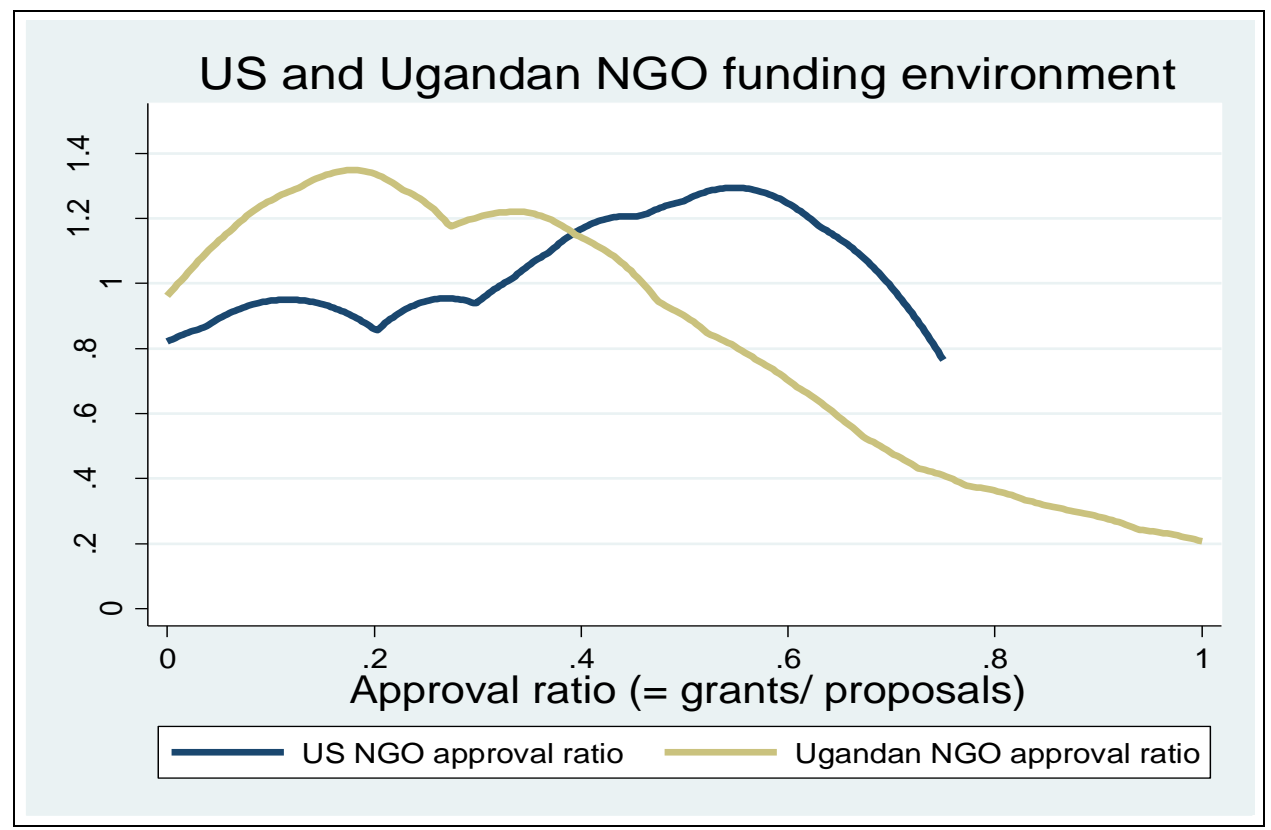

Figure 5. Distribution of approval ratios between samples.

There were much higher response rates among Ugandan NGOs, but results were much different. Due to a lack of significance, statistical results are not shown here, but can be reviewed in Tables A2 and A3 of the Appendix. None of the stakeholder groups were statistically different from the control, though all groups neared the $10 \%$ significance level in one-sided tests against this group (probability that given stakeholder group 
saw a higher response rate than the control group: government $=0.1074$, donors and peers $=0.1337$, and beneficiaries $=0.1999)$. Although the Ugandan sample did not match my original hypothesis, its results highlight several substantive implications.

\section{US vs. Uganda: Substantive Discussion and Further Exploration of Anomalous Results}

There are telling implications of the fact that my two samples should elicit such different results. As my sample size is small, inferences are limited, but the observed trends still have interesting substantive implications.

The obvious question is: why did Ugandan NGOs care about all stakeholder groups equally as opposed to the selective prioritization that was observed in the US sample?

The quintessential thing to consider is the funding environment in which these separate samples find themselves. As discussed in my theory section, the perception of the quasi-random assignment of funding can lead to adverse effects among nongovernmental organizations. Thus, if funding decisions were found to be more volatile in either Uganda or the US, NGOs may be more likely to spread risk among various stakeholders. This is supported by the following figure and tests.

Table 3

Differences in Total Grant Approvals

\begin{tabular}{lll}
\hline & DV $=$ Grant approval (US) & DV = Grant approval (Uganda) \\
\hline Proposals & $0.562^{* * *}$ & $0.12^{*}$ \\
Years in operation & $(0.06)$ & $(0.07)$ \\
& $0.045^{*}$ & 0.069 \\
Number of staff & $(0.023)$ & $(0.043)$ \\
& $-0.096^{*}$ & 0.008 \\
Donors & $(0.048)$ & $(0.007)$ \\
Beneficiaries & 0.125 & $1.509 * *$ \\
& $(1.213)$ & $(0.725)$ \\
Peer & -1.103 & 1.152 \\
& $(1.405)$ & $(0.693)$ \\
Government & -0.86 & 0.741 \\
& $(1.4)$ & $(0.854)$ \\
Constant & -1.788 & 0.463 \\
Summary stats & $(1.33)$ & $(0.58)$ \\
$\mathrm{R}^{2} /$ adjusted $\mathrm{R}^{2}$ & 0.0002 & -0.729 \\
$n$ & $(1.218)$ & $(0.773)$ \\
\hline
\end{tabular}

Notes: Control is the baseline group. Basic OLS regressions in which non-robust standard errors are reported in parentheses in Regression 1 and heteroskedastic robust standard errors are reported in Regression 2. Statistical significance is reported at the 0.01 $(* * *), 0.05(* *)$, and $0.1(*)$ levels.

Figure 5 shows grant approval ratios among NGOs in the US and Uganda. Grant approval ratios were calculated using the survey measures of total proposals and total approved grants within the last year for each organization. Since both grant application and approval measures were normally distributed among both samples, it is more probable that these distributions provide a representative view of the funding environment of each country. Given this measure, a country with a high average of grant approval ratios among NGOs would denote a more established and less random funding environment. Notice in this graph that such a 
distinction occurs as the mean of the US distribution is much higher than the mean of the Ugandan distribution. This supports the possibility of a more volatile funding environment on average in the Ugandan NGO market.

This argument is further supported by the following tests. The dependent variable in each column in Table 3 is the total number of grant proposals approved among NGOs within the different samples (US and Uganda) in the last year. I ran regressions on these variables to see which NGO characteristics explained higher rates of grant approval. In these tests, the US sample showed that the quantity of submitted proposals had a strong positive correlation with the grant ratio. Also, the $\mathrm{R}^{2}$ in the US regression is very high, denoting that most of the variance in approval ratios can be attributed to the amount of proposals written.

However, in the Ugandan sample, the explanation of variance in the dependent variable is much lower (only about 14\%). Also, although the correlation of proposals on the dependent variable was also positive, it was much weaker substantively and not statistically significant at the 0.05 level.

These results highlight a probable difference between the two funding environments - a given organization in the US could have much more confidence in receiving funding than a comparable organization in Uganda. In fact, an average Ugandan NGO would have to produce about eight proposals to receive an additional grant while a comparable NGO in the US would only have to produce about two, ceteris paribus. Further estimation of the size of these effects is shown in Figure A6 in the Appendix. Regression results are reported below.

In answer to the question of sample differences, I have presented strong evidence that there are differences in the funding environments between the two countries. This implies that it is harder for Ugandan NGOs to receive funding. In this environment, it is probable that NGOs would attempt advertising and accountability practices to multiple stakeholder groups in order to increase the overall probability of receiving funds and support.

\section{Conclusions}

I have performed a randomized controlled trial in order to see accountability trends among NGOs in the US and Uganda. I have learned that NGOs have strong incentives to be accountable to their donors as well as other stakeholder groups. In the US, accountability is much more focused toward donors than to other groups, which was consistent with my original hypothesis. In Uganda, priorities are high toward all stakeholders. My results also point to a strong connection between NGO funding environments and the formation of their accountability priorities.

In future tests I hope to increase response rates and run more robust statistical analyses - such as multinomial probit models - on my test results. I would also like to increase the breadth of the study by observing trends in other African countries. I believe that the implications of this experiment are important to stakeholder-NGO relationships, thus I think both sides of the market would eventually find it helpful to review such research initiatives. The fact that NGOs choose to participate at all in my survey suggests that they are willing to overcome the current asymmetries in the market, even in the face of possible public scrutiny. This supports the possibility that NGOs can eventually coordinate to bridge information gaps, thereby reducing investment risks among their potential stakeholders and accountability risks among themselves.

Standardizing evaluation measures would be a big step among NGOs toward increasing meaningful information for donors and other stakeholders. This assumes that stakeholders would choose to base their funding decisions on such accountability mechanisms, but this assumption is a probable conjecture given my 
theoretical framework and that stakeholders want to reduce investment risks wherever possible. I hope that through the results of this and future studies, both NGOs and stakeholders can learn of such possibilities so that they might work to build and maintain such standardized systems in the near future.

\section{References}

Atwood, J. B., McPherson, M. P., \& Natsios, A. (2008). Arrested development-making foreign aid a more effective tool. Foreign Affairs, 87(6), 123-132.

Banerjee, A. V. (2007). Inside the machine: Toward a new development economics. Boston Review, 32(2), 12-18.

Baranyi, S., \& Kristiana, P. (2005, August 11). Fragile states, gender equality and aid effectiveness: A review of donor perspectives. For the Gender Equality Division (YWD): Policy Branch Canadian International Development Agency (CIDA).

Barr, A., Fafchamps, M., \& Owens, T. (2005). The governance of non-governmental organizations in Uganda. World Development, 33(4), 657-679.

Ben-Ner, A. (1994). Review: Who benefits from the nonprofit sector? Reforming law and public policy towards nonprofit organizations. The Yale Law Journal, 104(3), 731-762.

Bollen, K., Paxton, P., \& Morishima, R. (2005). Assessing international evaluations: An example from USAID's Democracy and Governance Program. American Journal of Evaluation, 26(2), 189-203.

Bourguignon, F., \& Sundberg, M. (2007). Aid effectiveness: Opening the black box. The World Bank. Retrieved August 2, 2011, from http://siteresources.worldbank.org/DEC/Resources/Aid-Effectiveness-MS-FB.pdf

Burger, R., \& Owen, T. (2008). Promoting transparency in the NGO sector: Examining the availability and reliability of self-reported data. Centre for Research in Economic Development and International Trade, University of Nottingham.

Burger, R., \& Owen, T. (2011). Receive grants or perish? The survival prospects of African nongovernmental organizations. Centre for Research in Economic Development and International Trade, University of Nottingham.

Center for Global Development. (2006). When will we ever learn? Improving lives through impact evaluation. Retrieved August 1, 2011, from http://www.cgdev.org/section/topics/aid_effectiveness

Chapman, D. W., \& Quijada, J. J. (2009). An analysis of USAID assistance to basic education in the developing world, 1990-2005. International Journal of Educational Development, 29, 268-280.

Deaton, A. (2010). Instruments, randomization, and learning about development. Journal of Economic Literature, 48(1), 424-455.

Desai, M. A., \& Yetman, R. J. (2005). Constraining managers without owners: Governance of the not-for-profit enterprise. No. w11140. National Bureau of Economic Research.

Duflo, E. (2004). Scaling up and evaluation. In F. Bourguignon \& B. Pleskovic (Eds.), Annual World Bank Conference on Development Economics: Accelerating Development (pp. 341-369). Washington, D.C.: World Bank; Oxford and New York: Oxford University Press.

Edwards, M., \& Hulme, D. (1998). Too close for comfort? The impact of official aid on nongovernmental organizations. World Development, 24(1), 961-973.

Flack, T., \& Ryan, C. (2005). Financial reporting by Australian nonprofit organizations: Dilemmas posed by government funders. Australian Journal of Public Administration, 64(3), 69-77.

Hansmann, H. (1987). Economic theories of nonprofit organization. The nonprofit sector: A research handbook, 1, $27-42$.

Johnson, E., \& Prakash, A. (2006). NPNGO research program: A collective action perspective. Prepared for presentation at the Annual Convention of The Midwest Political Science Association, Chicago (April).

Kilby, P. (2004). Accountability for empowerment: dilemmas facing non-governmental organizations. World Development, 34(6), 951-963.

Knack, S. (2004). Does foreign aid promote democracy? International Studies Quarterly, 48(1), 251-66.

McGann, J., \& Johnstone, M. (2006). The power shift and the NGO credibility crisis. Brown Journal of World Affairs, 11 (2), 159.

McMahon, E. R. (2001). Assessing USAID's assistance for democratic development: Is it quantity versus quality? Evaluation, 7(4), 453-67.

Michaelowa, K., \& Borrmann, A. (2006). Evaluation bias and incentive structures in bi and multilateral aid agencies. Review of Development Economics, 10(2), 313-329.

Miguel, E., \& Kremer, M. (2004). Worms: Identifying impacts on education and health in the presence of treatment externalities. Econometrica, 72(1), 159-217. 
Milner, H. V. (2004). Why multilateralism? Foreign aid and domestic principal-agent problems. Columbia University. Retrieved from http://www.wcfia.harvard.edu/seminars/pegroup/milner.pdf

Prakash, A., \& Gugerty, M. K. (2010). Trust but verify? Voluntary regulation programs in the nonprofit sector. Regulation and Governance, 4(1), 22-47.

Svensson, J. (2006). The institutional economics of foreign aid. Swedish Economic Policy Review, 13(1), 115-137.

Thomas, V. (2010). Evaluation systems, ethics, and development evaluation. American Journal of Evaluation, 31(4), $540-548$.

USAID. (2011). USAID evaluation policy. Retrieved August 1, 2011, from http://www.usaid.gov/evaluation/

\section{Appendix 1}

I present first copies of my email invitations. The treatment language is found in the second and third sentences of the second paragraph. I sent the email as a representative

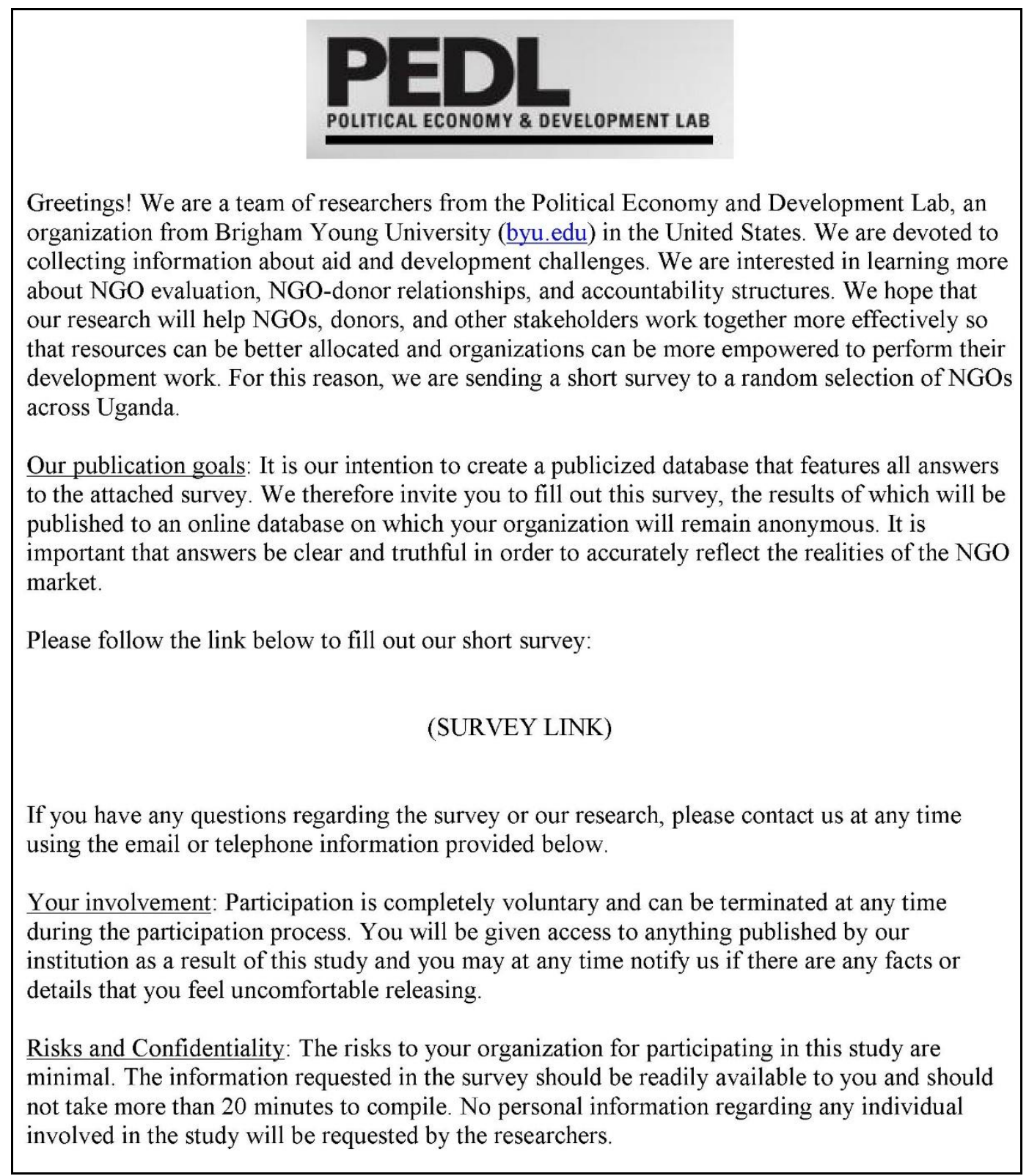

Figure A1. Control email invitation to fill out online survey.

Note. In filling out the survey and compiling the relevant documents, collaboration with staff is acceptable. 
For the rest of the figures, I will show only the second paragraph as it was the only part that differed between treatment groups. These treatments are shown as follows.

Our publication goals: It is our intention to create a publicized database that features all answers to the attached survey. We therefore invite you to fill out this survey, the result of which will be published to the donors of your organization. It is important that answers be clear and truthful in order to accurately reflect your dedication to your donors.

Figure A2. Email invitation to the donor group, second paragraph.

Our publication goals: It is our intention to create a publicized database that features all answers to the attached survey. We therefore invite you to fill out this survey, the result of which will be published to your project beneficiaries. It is important that answers be clear and truthful in order to accurately reflect your dedication to your beneficiaries.

Figure A3. Email invitation to the beneficiary group, second paragraph.

Our publication goals: It is our intention to create a publicized database that features all answers to the attached survey. We therefore invite you to fill out this survey, the result of which will be published to the local government officials in your area. It is important that answers be clear and truthful in order to accurately reflect your dedication to your local government officials.

Figure A4. Email invitation to the government group, second paragraph.

Our publication goals: It is our intention to create a publicized database that features all answers to the attached survey. We therefore invite you to fill out this survey, the result of which will be published to other NGOs working on similar development projects. It is important that answers be clear and truthful in order to accurately reflect your dedication your NGO peers.

Figure A5. Email invitation to the peer NGO group, second paragraph.

Table A1

Characteristics Among US NGO Groups

\begin{tabular}{llllll}
\hline & DV = Control & DV = Donors & DV = Beneficiaries & DV = Peers & DV = Government \\
\hline Grant approval ratio & 4.934 & $8.033^{*}$ & -1.66 & -0.966 & -3.751 \\
(grants approved/ & $(8.722)$ & $(4.598)$ & $(2.766)$ & $(1.977)$ & $(2.479)$ \\
proposals submitted) & -0.163 & -0.052 & -0.044 & 0.003 & 0.053 \\
Years in operation & $(0.221)$ & $(.0623)$ & $(0.081)$ & $(0.032)$ & $(.048)$ \\
& 0.244 & 0.118 & - & 0.022 & -0.073 \\
Current number of staff & $(0.432)$ & $(0.104)$ & -0.515 & -0.917 & $(.074)$ \\
Constant & -3.932 & $-3.672 *$ & $(0.916)$ & $(1.028)$ & $(0.386$ \\
Summary stats & $(5.922)$ & $(2.138)$ & & & $0.965)$ \\
Pseudo R & & & 0.1863 & 0.0545 & 0.2641 \\
$n$ & 0.3306 & 0.5026 & 13 & 13 & 13
\end{tabular}

Notes. These are probit models with non-robust standard errors reported in parentheses. Statistical significance is reported at the $0.01(* *), 0.05(* *)$, and $0.1(*)$ levels.

Next are the difference-in-proportions tests for Ugandan NGOs (see Table A1). These results have not been included in the text due to the lack of statistical significance in any of the relationships. Though, it is interesting to note that all stakeholder groups neared the one-sided $10 \%$ significance level when compared individually to the control group.

Characteristics of US NGOs are featured below. These probit models use the treatment groups as dependent variables in order to show what variables explain a given NGO's choice to be accountable to a certain stakeholder group. The only significant result is in the second regression where the donor group is the dependent variable. Here, a given organizations grant ratio is positively correlated at the $10 \%$ level to the proportion of donors among the other stakeholder groups. This implies that NGOs with more successful grant 
approval histories are more likely to care about donors opinions on average.

Table A2

Differences in Proportions Among Ugandan NGOs

\begin{tabular}{llllll}
\hline Stakeholder group & $\mathrm{p}<$ Control & $\mathrm{p}<$ Donors & $\mathrm{p}<$ Beneficiaries & $\mathrm{p}<$ Peers & $\mathrm{p}<$ Government \\
\hline Control & - & 0.8663 & 0.8001 & 0.8663 & 0.8926 \\
Donors & 0.1337 & - & 0.3943 & 0.5 & 0.5525 \\
Beneficiaries & 0.1999 & 0.6057 & - & 0.6057 & 0.6554 \\
Peer NGOs & 0.1337 & 0.5 & 0.3943 & - & 0.5525 \\
Government & 0.1074 & 0.4475 & 0.3446 & 0.4475 & - \\
$n=$ & 28 & 36 & 34 & 36 & 37 \\
mean $=$ & 0.1637 & 0.2105 & 0.1988 & 0.2105 & 0.2164 \\
std. dev. $=$ & 0.3711 & 0.4089 & 0.4003 & 0.4089 & 0.413 \\
\hline Notes: One-sided
\end{tabular}

Notes: One-sided difference in proportions tests. Each cell features the probability that the mean proportion of the row group is lower than the mean proportion of the column group. Summary statistics are also reported for the column group in the last three rows. Statistical significance is reported at the $0.01(* *), 0.05(* *)$, and $0.1(*)$ levels.

Table A3

Characteristics Among Ugandan NGO Groups

\begin{tabular}{llllll}
\hline & $\mathrm{DV}=$ Control & $\mathrm{DV}=$ Donors & $\mathrm{DV}=$ Beneficiaries & $\mathrm{DV}=$ Peers & DV = Government \\
\hline Grant approval ratio & $-2.472^{*}$ & $1.446^{*}$ & 0.548 & -0.034 & -0.581 \\
(grants approved/ proposals submitted) & $(1.293)$ & $(0.792)$ & $(0.844)$ & $(1.104)$ & $(0.637)$ \\
Years in operation & 0.09 & -0.018 & 0.047 & -0.075 & -0.047 \\
& $(0.064)$ & $(0.037)$ & $(0.05)$ & $(0.05)$ & $(0.044)$ \\
Current number of staff & 0.007 & -0.005 & $-0.032^{* *}$ & -0.002 & 0.014 \\
Constant & $(0.008)$ & $(0.01)$ & $(0.013)$ & $(0.012)$ & $(0.009)$ \\
Summary stats & $-1.816^{* *}$ & $-0.952^{* *}$ & -0.912 & -0.517 & -0.084 \\
Pseudo R & $(0.731)$ & $(0.464)$ & $(0.639)$ & $(0.543)$ & $(0.498)$ \\
$n$ & & & & & 0.0595 \\
& 0.2152 & 0.0791 & 0.0831 & 0.0627 & 0.059 \\
\end{tabular}

Note. These are probit models with non-robust standard errors reported in parentheses. Statistical significance is reported at the $0.01(* * *), 0.05(* *)$, and $0.1(*)$ levels.

Table A4

Randomization Checks Among US NGOs

\begin{tabular}{lllll}
\hline & DV = Years in operation & DV = Number of staff & DV = Approval ratio & DV = Collaboration \\
\hline Donors & -11.357 & 0.125 & 0.242 & -2.5 \\
& $(9.221)$ & $(9.963)$ & $(0.266)$ & $(1.862)$ \\
Beneficiaries & -10.024 & -5.5 & -0.167 & 0.25 \\
& $(10.65)$ & $(6.849)$ & $(0.343)$ & $(1.178)$ \\
NGO Peers & 1.976 & -3.633 & -0.083 & 2.5 \\
& $(13.133)$ & $(5.817)$ & $(0.298)$ & $(1.442)$ \\
Government & -4.407 & 5.267 & -0.117 & $(1.5)$ \\
Constant & $(10.221)$ & $(9.716)$ & $(0.272)$ & $3.5 * * *$ \\
Summary stats & $22.857 * *$ & $12.833^{* *}$ & 0.333 & $(0.833)$ \\
$\mathrm{R}^{2} /$ adjusted $\mathrm{R}^{2}$ & $(8.62)$ & $(5.481)$ & $(0.243)$ & $0.4420 / 0.2188$ \\
$n$ & & & & $0.4446 / 0.1668$ \\
\hline
\end{tabular}

Note. Control is the baseline group: OLS regressions; Regressions 1 and 2 report heteroskedastic robust standard errors while 
Regressions 3 and 4 are run non-robust. Statistical significance is reported at the $0.01(* * *), 0.05(* *)$, and $0.1(*)$ levels.

Table A3 shows NGO characteristics among NGOs in Uganda. As in the US tests, dependent variables were the different treatment groups. In these probit models, the only result of note is a significantly negative correlation between the current number of staff of a given organization and that organization's likelihood to be found within the beneficiary treatment group. This implies that smaller organizations care more about the opinions of their beneficiaries, perhaps due to more personal interactions and closer proximity.

\section{Table A5}

Randomization Checks Among Ugandan NGOs

\begin{tabular}{lll}
\hline & DV = Years in operation & DV = Number of staff \\
\hline Donors & -2.051 & -3.436 \\
& $(1.951)$ & $(5.805)$ \\
Beneficiaries & -0.711 & -3.077 \\
& $(2.157)$ & $(6.172)$ \\
NGO Peers & 0.562 & -3.122 \\
Government & $(2.258)$ & $(5.551)$ \\
Constant & -1.787 & 2.145 \\
Summary stats & $(2.07)$ & $(7.153)$ \\
$\mathrm{R}^{2}$ & $11.211^{* * *}$ & $14.895^{* * *}$ \\
$n$ & $(1.733)$ & $(5.126)$ \\
\hline
\end{tabular}

Note. Control is the baseline group: OLS regressions; both regressions report heteroskedastic robust standard errors. Statistical significance is reported at the $0.01(* *), 0.05(* *)$, and $0.1(*)$ levels.

Table A6

Differences in Ugandan and US NGO Practices

\begin{tabular}{llll}
\hline Structure & $\mathrm{p}:$ US = Uganda & Mean difference: US = 1 (CI) & n: US/ Uganda \\
\hline Grant approvals & 0.8559 & 0.126 & $44 / 19$ \\
& & $(-1.29,1.54)$ & $46 / 20$ \\
Grant proposals & 0.2479 & 1.33 & $114 / 41$ \\
Years in operation & $0.0182 * *$ & $-6.96,3.63)$ & $112 / 39$ \\
Current number of staff & 0.8920 & $(-12.67,-1.24)$ & 0.50 \\
\hline
\end{tabular}

Notes. These are two-sided difference-in-means tests. All tests are performed controlling for unequal variances between samples. 95\% confidence intervals (CIs) are reported in parentheses under the estimated mean differences between samples. The number of observations in each sample is also shown. Statistical significance is reported at the $0.01(* * *), 0.05(* *)$, and $0.1(*)$ levels.

The next two tables report the results of randomization checks for both samples (US first, Uganda second). In each sample, regressions are run using control variables as dependents (see Table A4 and Table A5). If samples are random, there should be no statistical differences between stakeholder groups in any of the regression. Such is the case in all US and Ugandan regressions denoting that the control variables were evenly distributed among NGOs selected for each treatment group.

Table A6 reports difference in control variables across samples-difference in means tests were run with the null hypothesis that US and Ugandan samples had equal means for each variable. Results show that the two samples do not statistically differ except in Years of operation which shows that US NGOs are older by about 
seven years on average.

This last figure shows predictions for grant approvals at different stages of a given NGO's life. I vary the number of proposals written and donor accountability in order to show differences between samples. These values are estimated using the regressions in Table 3 of the text. The results show that Ugandan NGOs are far outpaced by US NGOs unless Ugandan NGOs are found in the donor accountability group. This implies that it is much harder for NGOs in Uganda to receive funding through proposals written to donors.

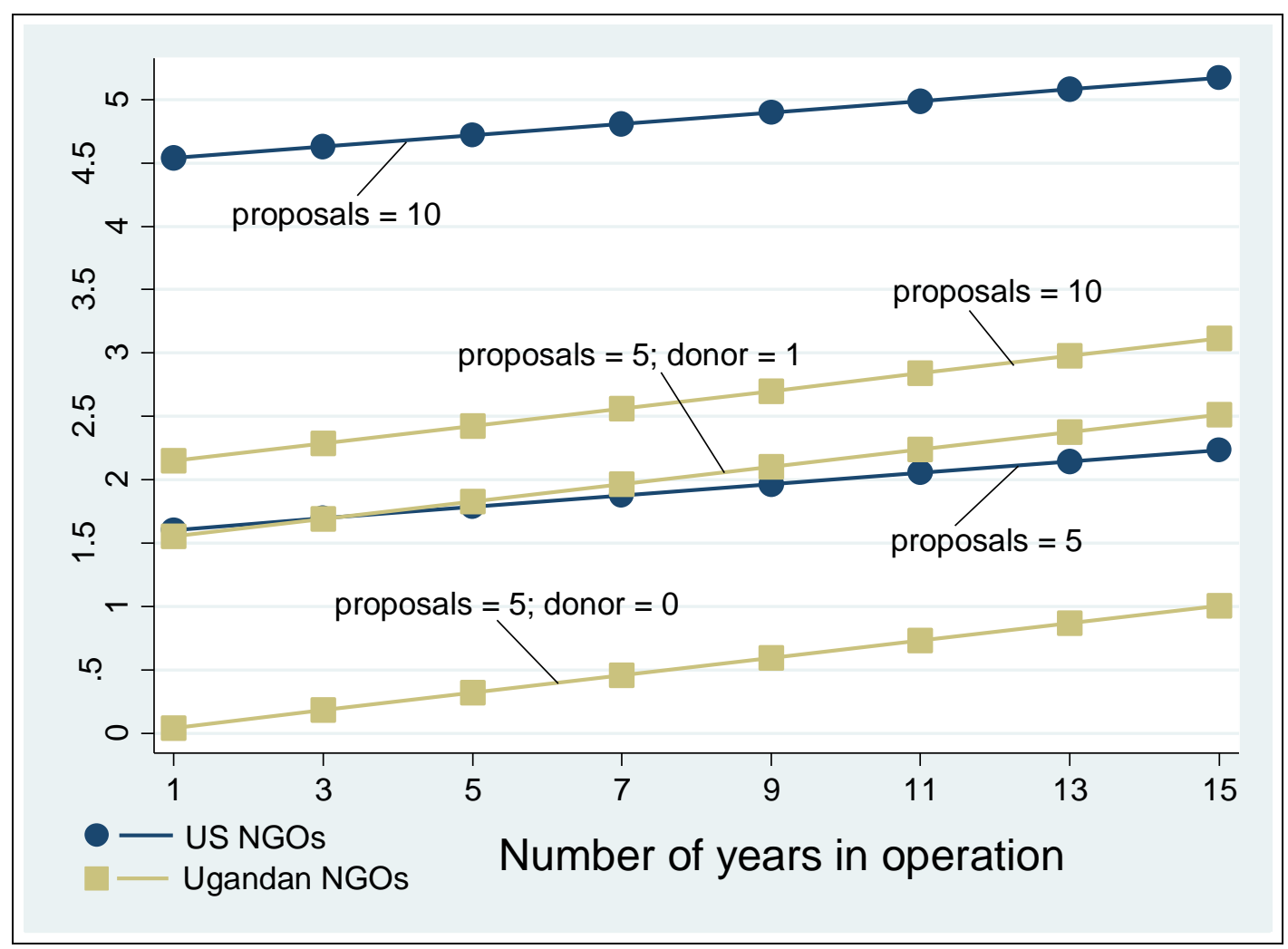

Figure A6. Estimated sustainability among NGOs in US and Uganda. 